\title{
Preferences and Uses of a Remote Lab from the Students' Viewpoint
}

\author{
http://dx.doi.org/10.3991/ijoe.v12i03.5468 \\ F. Lerro and S. Marchisio \\ Universidad Nacional de Rosario, Rosario, Argentina
}

\begin{abstract}
This paper aims to present new evidence and findings that enhance and enrich the knowledge of the preferences and uses of the remote laboratories from the students' viewpoint. Specifically, the study aims to recognize the students' preferences in selecting the remote lab as a learning resource, beyond the uses promoted by the professorship. Likewise, we seek to know the reasons given by students that support those preferences. The research was conducted at Facultad de Ciencias Exactas, Ingeniería y Agrimensura (FCEIA), Universidad Nacional de Rosario (UNR), Argentina, by using the "FCEIA-UNR Electronics Physics Remote Lab" and involving almost 300 students in the second year of Electronic Engineering. The lab is integrated into the e-ducativa Learning Management System (LMS), Facebook and Twitter, allowing the students to log in without additional authentication, both from the virtual classroom or from those social networks. We have collected empirical evidence from both, users' opinions and productions, and also, from registers of the remote lab itself, involving more than 4000 successful tests completed on the lab's database. We have achieved both qualitative and quantitative data that allow us to get a comprehensive study from the students' perspective.
\end{abstract}

Index Terms-remote labs; social networks; engineering education

\section{INTRODUCTION}

The first version of the "FCEIA-UNR Electronics Physics Remote Lab" (http://labremf4a.fceia.unr.edu.ar/) was developed in 2007 [1]. Since then, it has been used by the students of Electronics' Physics at the second year of Electronic Engineering.

In the context of the syllabus, the subject represents the first approach of the students to specific issues of the career. We present the subject in such a way that the students integrate the scientific and the technological backgrounds of electronic devices. It implies working on the usefulness of the semiconductor devices but also on the way in which they are "built", how they work and also on their potentialities, linking curves, structures, concepts, polarization modes and technical usages.

Traditionally, we offer the students various learning materials which contain theoretical background and exercises, such as: written modules, study guides, software simulations [2], a hypermedia system [3] and experimentation guides to be performed at the physical laboratory

In this context, the "FCEIA-UNR Electronics Physics Remote Lab" allows conducting experiments involving a variety of electronic devices: different diodes, bipolar transistors, field effect transistors and unijunction transistors. Among the great variety of didactic resources, the remote laboratory is considered a tool "at the service of" the student's learning process that can be integrated at any time to support learning activities [4].

The lab is available for the students to be used freely, but, from the professorship, the employment of the remote lab is mostly articulated with regular courses by means of guided observation of any teaching activity in theoretical classes as well as in compulsory practical activities on two themes: bipolar transistors and diodes.

In this context, we can say that the remote lab is being used as a teaching resource to support and include the experimental observation as part of theoretical construction and also, to guide further analysis of the behavior of basic electronic components, this way it complements traditional experimentation [5].

In any case, the challenge is to include the remote lab to the Physics curriculum making students develop strategies that would add value to the learning processes whenever the student requires them, by developing experimental activities, for which, the best known learning management systems (LMS) are limited [6].

Nowadays our lab is integrated into the e-ducativa Learning Management System (LMS) [7], Facebook and Twitter [8], which enables students to log in without any additional authentication system, both from the virtual classroom, as from the two social networks mostly used by them.

Moreover, our FCEIA-UNR Remote Laboratory has been federated to WebLab-Deusto [9], so our users can access their Laboratories as well as the ones that are connected to them. In the same way, WebLab-Deusto's users can access the FCEIA-UNR lab.

Since 2007, over 270 students have employed this remote laboratory. We have collected empirical evidence from users' opinions and productions, and also, from registers of the remote lab itself.

We gathered both qualitative and quantitative data that allow us to get to a comprehensive study from the students' perspective regarding the integration of the remote lab in a curricular context.

This paper aims to socialize our findings that emerge from the analysis of those data. This study specifically aims to recognize the students' preferences in selecting the remote lab as a learning resource, beyond the uses promoted by the professorship.

Likewise, we seek to know the reasons given by students that support those preferences as well as the considerations provided by students, with reference to the uses promoted by the professorship 


\section{Methodology}

\section{A. The Remote Laboratory Platform as a Data Source}

On each test performed by the students, certain information is saved on the Lab's Server: username, method of logging in, date/time, chosen circuit and the different options available on each circuit to be tested (i.e. if the student applied to test the whole curve, or if he / she has selected certain values, or if he / she asked to perform the test under different temperatures, among other possible experimental conditions).

266 students logged in and performed, at least, one remote laboratory test since 2007.

Applying statistical descriptive analysis, we can identify the entry mode most frequently used; and also, from each student, we can identify which tests were carried out, as well as how many times the student performed it, among others.

But the quantitative results are limited in that they provide numerical data rather than illustrative knowledge to understand more about students' selections. So, to complement and deepen the quantitative study, we searched for qualitative data [10].

\section{B. Searching for Qualitative Data}

The research instruments used to collect qualitative information were:

- The final reports on the tests performed by the students

- The questionnaire prepared to collect judgments and opinions from students

\section{1) The final reports}

The final reports on experimental activities that the engineering students at UNR performed, using the remote laboratory, stand as interesting research resources for this purpose.

The syllabus units which include the students' use of the remote laboratory are the ones related with $\mathrm{P}-\mathrm{N}$ junction diodes and bipolar junction transistors.

In order to gather the information for this research, we have carried out the following methodological strategy.

First, we have introduced the topics through graphs, animation and applets [11] [12] and face-to-face explanations. Then, we have showed the students the remote lab equipment; we have discussed the clear differences that stand out when working with this remote access "real laboratory" through Internet and students' frequently used applets simulations. We also have mentioned the students the differences in relation to the basic constructive characteristics, the nature of the information accessed in each case and the user's interpretation of the given information. At the same time, the students have watched an experiment on the equipment to check how the lab reacted to the operator's decisions, and how the light indicator turned on when the corresponding element was being tested. We also have explained how the laboratory works, its resources, operating capacity and possible tests to be performed.

After the students had their first contact with the remote laboratory and once the first issue about the topic P-N junction diodes was over, we asked the students to solve the activities that follow:
- Study the behavior of different junctions (i.e. rectified diodes of silicon and germanium, led diode, zener diode, emitter-base junction and base-collector junction of different bipolar transistors), and make deductions from their building characteristics.

- Get parameters which characterize all the P-N junctions to be experimented in the remote laboratory and give explanations of the physical processes involved (particularly recombination, diffusion and drift processes).

As we can see, the activities were presented to students as open problems, without precise guidance on the steps to be followed in order to be solved by them.

Solving these problems required from students making decisions with reference to what device must be tested and under which conditions; which points of the experimental curves were the most interesting for the required analysis, which were the concepts that were involved and the connections between the theories and experimental results, among others.

The students should perform each of the experiments individually, but they were encouraged in order to analyze the results and inform them to the professor in a group report (no more than 3 people).

The allowed time to send the written report to the teacher is two weeks, in accordance with the time devoted to the treatment of the topic in the syllabus.

We have gathered 87 reports between 2008 and 2015.

In their reports the students included a brief description of the tests performed and some graphics and images of each test. Sometimes they added a list of very concrete evaluative considerations and suggestions with regard to the remote laboratory system and each particular test.

2) The questionnaire prepared to collect judgments and opinions from students

Once the students have completed successfully the examination of the topic, the professors sent the students a questionnaire composed by five open questions.

We asked the students

- If the remote laboratory was a helpful resource for their learning process; and, on this basis, we asked to draw up a brief explanation of their own answer.

Likewise, we requested the students:

- To evaluate the functionality of the remote laboratory;

- To explain whether it should be used to a greater extent in the syllabus, i.e. including more topics of the subject-matter; and

- To express what were the uses that they gave to the remote laboratory, beyond those proposed by the professorship.

Referring to this, we considered appropriate to suggest the students to think about learning situations and previous experience in ICT usage, before answering the questionnaire, in order of not underestimating the potential influence of contextual factors such as:

- Operative difficulties regarding access and usage of the remote laboratory 
- Methods of incorporating ICT (thinking about applet simulations, hypermedia, LMS), as learning resources

- The learning activities they perceive to be fruitful

We only sent the questionnaire to the 216 students who had completed the examination successfully. The response to the questionnaire was not compulsory.

Finally, 134 students answered the questionnaire.

\section{Content Analysis and the Students' Viewpoint}

We carried out content analysis [10] of both, students' reports and questionnaire responses.

Content analysis is a method of analyzing and quantifying the materials used in human communication.

In general, it can be deeply analyzed in detail the content of any communication, regardless of the number of people involved (i.e. a person, a conversation, a mass communication) and can be used with a variety of instruments such as questionnaires, surveys, tests, books, interviews, among others [13].

In recent years this technique has abandoned the limits of media communication; so, content analysis is used to analyze the content of personal productions, complementing the analysis of data obtained through surveys, interviews, and observation records [14].

In addition, content analysis is defined as "a technique designed to formulate, based on certain data, reproducible and valid inferences that can be applied to a context"[15].

In order to obtain data, the textual information was organized through a categorization process. We analyzed students' answers and suggestions in order to identify semantic expressions associated with:

- The technical and operational difficulties related with the lab

- The helpfulness of the remote laboratory,

- The uses proposed by the teacher team,

- The effective uses gave by the students,

- Previous experience of the students on ICT

- The mandatory learning activities and the experimental tasks involved

Then, we have carried out the following steps:

- The individual reading of complete students' answers, comments, suggestions and reports;

- The identification of the different lexical elements (phrases, sentences, paragraphs) which activate representations,

- The definition of emerging categories,

- The association of the students 'answers according to their discourses

- The amount of similar responses in each category

We also analyzed any kind of students' individual or team accounts, even those representations such as the experimental curves that they could have included.

\section{RESULTS}

The overall number of tests performed by students was 4055 .

\section{A. From Quantitative Analysis}

\section{1) Entry mode most frequently used}

Figure 1 shows what has resulted from considering all the tests satisfactorily completed by students, by year and by entry mode (authorization login system): internal authorization; e-educativa LMS, Facebook, Twitter or WebLab-Deusto system.

It can be seen that from 2007 to $2012,100 \%$ of the experiments correspond to users that were authorized by the system itself.

This first result is obvious, since up 2012 there was no other method to $\log$ in the remote laboratory. The integration with e-ducativa platform was implemented in April's 2012 and accessing from WebLab-Deusto became available in November 2012.

Besides, we must consider that we implemented our laboratory's integration with Facebook and Twitter in September 2013.

Since that moment the entries using the authorization systems of social networks have prevailed over the other options. At that point, we emphasize that today and since September 2013, the students had been free to choose the access mode to the lab.

\section{2) The students and the mandatory tasks}

Since 2009 there have been more tests on second semesters than on the first ones (Figure 2). But we can also see a great increase in the "number of tests done" per period (e.g. 447 tests in 2009-2010 and 860 in 20132014).

This result cannot be explained by the increase of the "number of students" per period. Specifically, the review of the administrative data of the subject reveals that the lowest number of students was 48 in 2009 and the highest one was 54 in 2013.

As the terms of use proposed by the professorship have not changed and the number of students hasn't vary significantly, we consider that the increase in the number of tests performed by the students could be explained in terms of a variety of other possible reasons, such as: better conditions of accessibility, improvements made to the remote lab, greater appropriation of the remote lab by students, among others.

Figure 3 shows that the number of tests performed was high on the last months of each semester (i.e. June and December), and also in the months that the remote lab was introduced for the first time (May for the first semester and November for the second one).

Those results reveal that there was a great number of students that have waited until deadline to perform the tests; and also, that the students have been curious to use something new.

The remote laboratory allows the students to perform 31 different experiments.

There was students who have carried out more than 60 trials, covering all the devices, but others only did the necessary to comply with the mandatory activities.

It is important to remark that although the number of tests covering the topics diodes and bipolar transistor was 12 , some students tested only those they needed to answer the mandatory activities. 




Figure 1. Tests performed by auth login system

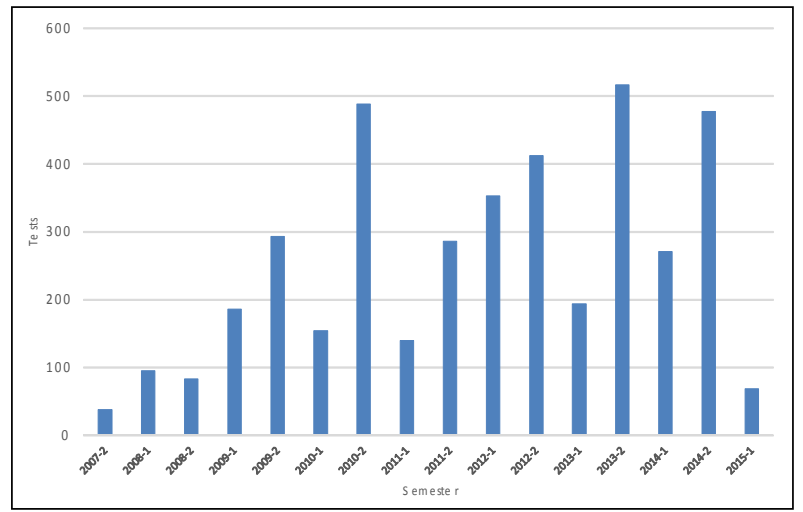

Figure 2. Tests performed by semester - (Semester 1 from March to July and Semester 2 from August to February)

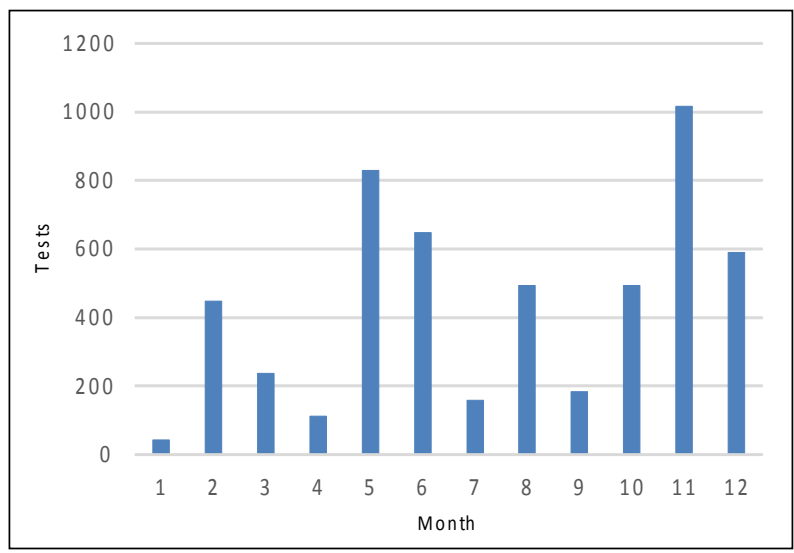

Figure 3. Tests performed by month

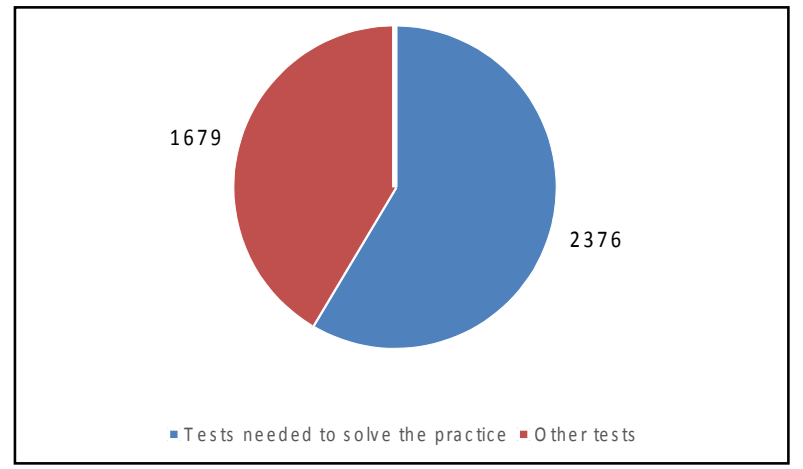

Figure 4. Type of tests made by students
Figure 4 shows how the total number of tests performed by students is distributed.

On one hand, there are the tests that students performed to solve the mandatory activities (59\%), and on the other hand, the tests performed by students freely (41\%).

\section{B. From the Qualitative Analysis}

The answers to the questionnaires allow us to know the reasons given by students about the other tests performed.

$98 \%$ of the total number of students, who answered the questionnaire, has argued that they were satisfied with the remote lab because it facilitated them the analysis of curves, and therefore, the understanding of the operation of the electronic devices.

Some students $(87 \%)$ have said that they preferred the remote laboratory rather than the simulations.

In relation to what was stated before, many students have argued that, in some cases, they made several tests involving the same device, in order to study the behavior of some specific points of the curve that did not seem right.

The students have expressed other reasons justifying the remote laboratory usage. Regarding the remote lab, they also have said that:

- It helped the understanding of the theoretical concepts and the phenomena;

- It facilitated to work through experiences in a way that would have not been possible in a traditional laboratory;

- It was very helpful for them to have the actual curves at any time, especially when the doubts arose.

They also have appreciated that the remote laboratory had been helpful in order to:

- Compare the results obtained by different test methods

- Improve the interpretation of the characteristic curves of the devices

- Deepen his/her knowledge about any device already tested in the traditional lab

- Make progress in the setting of the parameters which will allow him/her to elaborate the equivalent electric models

It is important to state that we didn't find any arguments concerning the presence of operational difficulties, neither on accessibility nor regarding the implementation of the tests in any part of the questionnaire nor in the reports.

When the students referred to the uses assigned to the remote laboratory by the teaching team, they have valued it as positive; furthermore, they also have appreciated both, the teamwork and their active involvement in carrying out the learning activities.

However, although all students submitted the reports of the activities by using the LMS, such as it was requested, $8 \%$ of the total number of students who answered the questionnaire, stated as a suggestion, that they would prefer to submit printed and individual reports.

\section{CONCLUSIONS}

Since 2007 we have been carrying out consecutive assessments of the curricular use of this remote laboratory. 
Briefly, we can say that the remote lab has provided opportunities to explore new teaching methodologies that make use of this technology in real contexts.

Also, after using the remote lab for 8 years and with all the improvements made to it, the amount and variety of data we had gathered enabled us the implementation of new analyses.

This paper presents new evidence and findings that enhance and enrich the knowledge of the preferences and uses of the remote laboratories from the students' viewpoint.

The analysis of the data collected from the lab's server, shows that if you give the students a simpler authentication system to $\log$ in that they are already accustomed to use, they will prefer it. Specifically, the students prefer to $\log$ in from the same social networks they usually use for other purposes, more than the LMS and the RLMS. They say that it seems simpler for them.

We conceive ICT as integrated didactic resources; furthermore, we conceived the assessment should be consistent with the developed teaching and learning activities. So, we take into account the process and teamwork, as well as individual outcomes; and, furthermore, the role of the remote lab as an integral part of the individual and group achievements. Furthermore, it is clear the necessity of including ICT in the curriculum in order to promote the development of the professional competences (not only technical ones but also social ones), which requires society today for sustainable development.

The students have evaluated as positively both the incorporation of the remote laboratory and the use of ICT in the learning process; moreover, they have assumed teamwork as an active and fruitful task. But, $8 \%$ of the students have said that they would prefer printed and individual reports. Based on this $8 \%$, we believe it is necessary to develop in students even more awareness about this type of goals and educational needs.

We emphasize that the use of remote labs as a complement of traditional labs, can add opportunities to learning students' in order to develop skills that involve modeling, design, problem solving, critical observation and analytical thinking. In this context, the design of the learning activities involving the remote lab usage is crucial.

In this case, the mandatory activities included a formulation of hypothesis plus the presentation of explanations considered scientifically right.

Furthermore, the students have taken decisions that show their autonomy, planning and choosing each experimental activity. They also have built up and put into practice relevant reflexive knowledge in concrete situations, have communicated the experimental results and have written scientific reports.

Finally, we highlight the importance of gathering both, qualitative and quantitative information, in order to complement the analysis and gain a better understanding of the problem.

\section{REFERENCES}

[1] F. Lerro \& M. Protano, "Web-based Remote Semiconductors Devices Testing Laboratory. International Journal of Online Engineering 2007, 3(3), 1-4. http://online-journals.org/i-joe/article/ view/432

[2] S. Marchisio, M. Plano, J. Ronco and O. Von Pamel. "Teaching Fermi-Dirac's statistics to engineering students with ICT simula- tion resources". Proceedings INTERTECH'2008 - International Conference on Engineering and Technology Education, Peruíbe, Brazil, March 02 - 05, 2008

[3] S. Marchisio, M. Plano, J. Ronco and O. Von Pamel. "Introducing hypermedia learning resources in a Physics course on semiconductor devices for electronic engineering students". Proceedings Internacional Conference on Engineering Education and Research "Progress Through Partbnership", Edit. Technical University of Ostrava, Czech Republic, 2004. (pp.297 - 305).

[4] F. Lerro, S. Marchisio, M. Plano, M. Protano and O. Von Pamel. "A remote lab like a didactic resource in the teaching of the physics of electronic devices". Proceedings 11th International Conference on Interactive Computer aided Learning; September $24-26$, 2008. Villach.

[5] F. Lerro, S. Marchisio, E, Perretta, M. Plano, M. Protano, "Using the Remote Lab of Electronics Physics ("Laboratorio Remoto de Física Electrónica”) to Support Teaching and Learning “ 2012. pp.211 -230. In García Zubía, J y Alves, G. (comp.) "Using Remote Labs in Education". Universidad de Deusto http://www.deusto-publicaciones.es/index.php/main/libro/913

[6] J. Garcia-Zubia, U. Hernandez, I. Angulo, P. Orduña, and Irurzun "Acceptance, usability and usefulness of weblab-deuJ. sto from the students point of view". International Journal of Online Engineering, 2009. 5. http://dx.doi.org/10.3991/ijoe.v5i1.817

[7] F. Lerro, S. Marchisio, S. Martini, H. Massacesi, E. Perretta, A. Giménez, N. Aimetti and J. Oshiro. "Performing Real Experiments from a Remote Learning Management System". IEEE Revista Iberoamericana de Technologias del Aprendizaje. February 2014. Volume: 9 Issue: 1. pp: 1-5. Digital Object Identifier: 10.1109/RITA.2014.2302052.

[8] F. Lerro, P. Orduña, S. Marchisio, J. García-Zubía. "Development of a Remote Laboratory Management System and Integration with Social Networks". International Journal of Recent Contributions from Engineering, Science \& IT (iJES) Vol 2, No 3. 2013. .pp3337. http://online-journals.org/index.php/i-jes/article/view/3821 http://dx.doi.org/10.3991/ijes.v2i3.3821

[9] P. Orduña, F. Lerro, P. Bailey, S. Marchisio, K. De Long, E, Perreta, O. Dziabenko, I. Angulo, D. Lopez-de-Ipina and J. Garcia-Zubia. "Exploring complex remote laboratory ecosystems through interoperable federation chains," Global Engineering Education Conference. IEEE. EDUCON 2013. pp.1200,1208 http://ieeexplore.ieee.org/stamp/stamp.jsp?tp=\&arnumber $=653025$ 9\&isnumber $=6530074$

[10] R. Bogdan and S. Biklen. Qualitative Research in Education. An Introduction to Theory and Methods. ERIC. 1988

[11] C.R. Wie. The Semiconductor Applet Service. 1998a.. http://jas.eng.buffalo.edu/

[12] C.R. Wie. "Educational Java Applets in Solid State Materials" IEEE Transactions on Education 41(4), 1998b. pp. (354-354). http://jas.eng.buffalo.edu/artcls/ieee/Educational Java Applets in Solid State Materials IEEE-TE41.p.354\%281998\%29.pdf

[13] O.R. Holsti. Content analysis. In Lindzey, G \& Aronson, E. The handbook of social Psychology. Vol 2. Research Methods, Addison-Wesley, Reading, Mass, 1968.

[14] G. Pérez Serrano. Investigación cualitativa II: retos e interrogantes. Técnicas y análisis de datos, 1994.

[15] K. Krippendorff. Metodología del análisis de contenido. Teoría y Práctica. Barcelona. Paidós Ibérica, S.A. 1990

\section{AUTHORS}

F. Lerro is with the Facultad de Ciencias Exactas, Ingeniería y Agrimensura - Universidad Nacional de Rosario (UNR), Avda. Pellegrini 250, Rosario, Argentina (e-mail: flerro2@yahoo.com.ar )

S. Marchisio is with the Facultad de Ciencias Exactas, Ingeniería y Agrimensura - Universidad Nacional de Rosario (UNR), Avda. Pellegrini 250, Rosario, Argentina (e-mail: timbucorreo@gmail.com)

This article is an extended and modified version of a paper presented at the ICL/WEEF 2015, held September 2015, in Florence, Italy. It was submitted on January $15^{\text {th }}, 2016$. This work was supported in part by the Project 19_I371: "Dispositivos y prácticas de enseñanza en Ingeniería" (Devices and teaching practices in Engineering). Secretaría de Ciencia y Tecnología. Universidad Nacional de Rosario, Argentina. Submitted 14 January 2016. Published as resubmitted by the authors 14 February 2016. 